\title{
Coping strategies for exam stress
}

\author{
Monica Elisabeta Păduraru ${ }^{1}$ \\ ${ }^{1}$ The Bucharest University of Economic Studies - Teachers' Training Department, Bucharest, Romania
}

\begin{abstract}
During the examination period, students experience a state of stress generated both by the exams themselves and by the fear of getting bad grades and implicitly a failure. This problem needs to be taken into consideration, not only because of the high percentage of students who suffer from it, but also because it has a negative effect on academic performance and self-esteem. Through this article, we tried to identify coping strategies used by students to cope with the exam stress (before, during and after the exam). We used the focus group technique on 32 students (divided into 4 groups). The students are from The Bucharest University of Economic Studies and they are enrolled in the pedagogical training module. Following the centralization of the opinions expressed during the discussions, we grouped the coping strategies into four categories: general coping (used during the semester), coping methods used before the exam (in the exam period), coping methods used during the exam itself, and coping methods used after the exam. As a result of this study, we believe that students and teachers have raised awareness of the importance of using positive coping strategies to lessen the stress associated with exams. The initiative to organize student stress management workshops was also launched..
\end{abstract}

Keywords. stress, examination, coping strategy.

\section{Introduction}

Stress is the automatic and natural response of the human body to situations that can be threatening or challenging. This entails a state of personal over activation in different real situations that the human being evaluates or considers as excessive and that appear in conditions where there are scarce resources or solution skills. For example, it may appear in the case of students due to an overload in academic tasks when there is very little time to complete them.

Being a student at present time means living in a state of constant pressure generated by a series of factors that are related to both the academic environment (the degree of difficulty of the subjects, the expectations of the teachers, the number of exams and their degree of difficulty, the pressure to maintain scholarships) as well as the non-academic one (family pressure, personal aspirations, economic difficulties). Often, these pressures on students can affect their emotional balance and their mental health (by which we understand emotional, psychological, and social well-being, which affects how we think, feel, and act. It also helps determine how we handle stress, relate to others, and make choices) (Mentalhealth.gov, 2018). There are studies that support previous statements, arguing that students are subjected to different types of stressors. Among these stressors we can find the pressure of academics with an obligation to succeed, an uncertain future and the difficulties of integrating into the system. Other sources of stress that students face are social, emotional and physical and family problems that may affect their learning ability and academic performance ${ }^{1}$ (Sreeramareddy et al., 2007).

A survey conducted by National Union of Students Scotland on 1.872 students from 19 colleges and 15 university campuses shows that examinations were found to be the biggest 
concern for students. An overwhelming $90 \%$ of students reported this caused them more stress than expected (National Union of Students Scotland, 2010).

\section{Related Work}

The study of stress has traditionally been governed by three conceptual aspects: stress as a stimulus; stress as a response, and stress as person-environment interaction (Laredo, 2015). Stress as a stimulus refers to scenarios that cause discomfort and alter or can alter the organism. These situations or events, called stressors, can be framed in different scenarios (examinations being some of them). Stress as an answer it is the physiological or psychological response that an individual manifests when facing an environmental stressor. The answers that occur in the individuals are hormonal, to which organic, functional and somatic stress reactions correspond. Stress as a stimulus-response interaction it is considered as a stimulus-response relationship, felt by the individual as threatening or overflowing its possibilities and threatening its well-being. The increase in the stress response depends mainly on perceptual aspects. The physiological activation triggered by the subject's evaluation of the situation and of their coping skills (primary and secondary evaluation) highlights, once again, the importance of cognitive aspects as determinants of the stress response (Lazarus, 1984).

Stress can occur before and during examinations and can have lasting negative impacts on the self-esteem of the student. Stress before and during examination is experienced by many normal students and the signs are easy to notice: irregular sleep, feeling of tiredness, isolated or sad, feeling ache all over, suffer from stomach upset, feeling of restlessness or leading to a condition where you are not able to recall whatever you studied (Jagrati, 2014).

According to Hernadez, Parra, Campoy, Garcia and Perez-Gallardo (2013) stress before the exams not only affects the academic performance but it is related to the emotional and health status of the students. Therefore the exams stress, together with the lifestyle of the students that in exam periods is modified can produce some unhealthy habits - excess in the consumption of caffeine, tobacco, psychoactive substances and even, in some cases, ingestion of tranquilizers - all the above, in the long run could lead to health disorders (Hernández, Parra, Campoy, García, \& Pérez-Gallardo, 2013).

According to the Romanian Education Law, the academic success of a student during a study program is determined by continuous and summative assessment (Romanian Education Law, 2011, section 7, Article 144, paragraph 1). The summative assessment of the students is done at the end of each semester, in the examination session, through oral, practical or written evaluation tests. Although exams are the same for all students, the way they relate to them and the level of stress experienced differs from case to case. Lazarus and Folkman's model emphasizes that cognitive processes for stress mediate the relationship between stressors and stress reactions (Lazarus, 1984). In this case, the cognitive processes include the estimation of the value of the stressors and the selection of coping strategies to cope with stressors (Higuchi, Echigo, 2016). The coping strategies used may vary: approach and avoidance strategies, problem and emotion-focused coping strategies, and behavioral and cognitive strategies (Higuchi, Echigo, 2016).

Most students perceive the time of the exam as something threatening and experience an increased anxiety state in front of it. In general, any difficult test subjects the candidates for two situations: the intrinsic difficulty of the questions and the possible distortion level of 
anxiety. It has been proven that while a moderate increase in the level of anxiety can be useful if motivates the student to increase their efforts and to focus their attention on the content of the test, a greater increase in anxiety may produce unsatisfactory results. In a study conducted in 2007 on students from two community colleges in southern Illinois, Pierceall and Keim found that the most often used activities to cope with stress included talking to family and friends, leisure activities, and exercising. Less desirable coping strategies were drinking alcohol, smoking, and using illegal drugs (Pierceall, Keim, 2007). Another study undertaken at Kathmandu University in 2005-2006 among 407 clinical sciences students has identified that the five most common coping strategies adopted by the students during the events of stress were positive reframing, planning, acceptance, active coping and self-distraction. The other identified strategies were: emotional support, instrumental support, religion, venting, self-blaming, use of humor, denial, behavioral disengagement, alcohol/drug use (Sreeramareddy et.al, 2007).

Pena (1998) shows that there are significant differences in ways of coping with stress used by the subjects in the previous stage of the examination compared to those used in the later stage is to say the subjects have the tendency in average to not use coping modes in the same proportion in the stages before and after the exam (Pena, 1998).

\section{Method}

To identify the sources of exam stress and coping strategies used by students to reduce stress related to exams, we used the focus group technique (Chelcea, 2007). A total of 32 students were divided into 4 groups. The students were from the Bucharest University of Economic Studies and they were enrolled in the pedagogical training module. Focus groups were conducted after the summer exam session. We selected to participate in focus groups the students who, after completing a self-perceived stress assessment questionnaire, fell into the "high stress" category. The duration of a focus group was 90 minutes. Questions focused on finding which ways of coping students use in order to reduce stress before and after the exams period.

\section{Results and Discussion}

During the discussions, the participants pointed out that stress related to the exam is not present only during the examination period but before and even after the examination. The causes of stress exams are varied and are related both to academic and non-academic aspects. We have grouped these stress causes in four categories: lifestyle, psychological factors, insufficient developed study skills, and academic factors. The first category - lifestyle - were included dysfunctional personal relationships, change in living environment, bad living conditions, change in sleeping habits, inadequate rest, insufficient physical exercise, new responsibilities, financial difficulties, combining work with studies, not scheduling available time, health problems, poor eating habits or poor nutrition, and too many stimulants. In the second category - psychological factors - were mentioned: feeling little or no control over the exam situation, unrealistic expectations, procrastination, future worries irrational beliefs, irrational thinking about exams and outcomes, irrational demands, and negative thinking and self-criticism. The causes of stress falling into the third category - insufficient developed study skills - are: language difficulties, reading without understanding, poor computer skills, inconsistent content coverage, not making revision notes, and all-night studying before 
exams. In the fourth category - academic factors - we have included: increased class workload, missing lectures, lecturers' expectations, course requirements, and many hours of studies.

Following the centralization of the opinions expressed during the discussions, we have grouped the coping strategies for exam stress into four categories: general coping strategies (used during the semester), coping methods used before the exam (in the exam period), coping methods used during the exam itself, and coping methods used after the exam. General coping strategies (used during the semester) are: a healthy lifestyle (enough exercise, good nutrition, adequate rest, and positive thoughts), good time management (planning the study and the free time), accurate information (regarding lecturers' expectations, course requirements). In the coping methods used before the exam (in the exam period) were mentioned: developing a timetable which include study and fun, leaving time to revise, taking breaks, good eating and sleeping habits, exercise, Consumption of coffee and energy drinks. In the category coping methods used during the exam itself students mentioned: keeping calm, read the instructions carefully, re-read the instructions a second time, and prioritize what need to be done. The last category - coping methods used after the exam - includes: avoid self-criticism, reward for the hard work, and plenty of rest.

\section{Conclusions (and Future Work)}

The stress associated with exams can be diminished by using coping strategies that can intervene before, during and after exams. These coping strategies can be developed and practiced over time. Some of them are related to the students' lifestyle, while others are related to academic life and its specific requirements. There are currently few activities within the university aimed at familiarizing students with coping techniques before, during and after examination periods. This is one of the issues underpinning our recommendations: organizing, within the university, work-shops to address stress management; promoting a balanced lifestyle for students, that should combine academic demands with a healthy lifestyle.

\section{REFERENCES}

Chelcea, S. (2007). Metodologia cercetării sociologice. Metode cantitative și calitative. București: Editura Economica.

Hernández, J. Á., Parra, J. M. A., Campoy, J. M. F., García, D. S., Pérez-Gallardo, E. R. (2013). El estrés ante los exámenes en los estudiantes universitarios. propuesta de intervención. International Journal of Developmental and Educational Psychology, no 1, vol. 2.

Higuchi D., Echigo A. (2016). Characteristics of coping strategies and the relationships between coping strategies and stress reactions in physical therapy students during clinical practice. Journal of Physical Therapy Science, 28(10): 2867-2870.

Jagrati, J. (2014). Examination Stress And Anxiety: A Study of College Students. Global Journal of Multidisciplinary Studies, vol. 4, issue 01.

Laredo, M. M. (2015). Stress in college students of Health Sciences. Revista Iberoamericana para la Investigación y el Desarrollo Educativo, vol 6, no 11.

Lazarus RS, Folkman S (1984). Stress, Appraisal, and Coping. New York: Springer.

Mentalhealth.gov. (2018). What Is Mental Health?. Retrieved from: https://www.mentalhealth.gov/basics/what-is-mental-health. 
National Union of Students Scotland. (2010). Silently Stressed. A survey into student mental wellbeing. Retrieved from: https://www.nus.org.uk/PageFiles/12238/THINK-POS-REPORT-Final.pdf.

Pena, A. Q. (1998). Estrés y afrontamiento del estrés frente al examen en educación superior: un estilo o un proceso?. Revista de Investigación en Psicología, vol 1, no 2.

Pierceall, E. A., Keim, M. C. (2007). Stress and Coping Strategies among Community College Students. Community College Journal of Research and Practice, Volume 31, 2007 - Issue 9.

Romanian Education Law. (2011). Retrieved from https://www.edu.ro/sites/default/files/_fi\%C8\%99iere/Minister/2017/legislatie\%20MEN/Legea\%20 nr.\%201_2011_actualizata2018.pdf

Sreeramareddy, C, Shankar, P. R, Binu, V. S., Mukhopadhyay, C., Biswabina, R., Menezes, R. G. (2007). Psychological morbidity, sources of stress and coping strategies among undergraduate medical students of Nepal. BMC Medical Education 7:26. 